\title{
Characterization of Lignanamides from Hemp (Cannabis sativa L. ) Seed and Their Antioxidant and Acetylcholinesterase Inhibitory
}

\section{Activities}

Xiaoli Yan ${ }^{\dagger}$, Jiajing Tang ${ }^{\dagger}$, Carolina Passos ${ }^{\S}$, Alessandra Nurisso ${ }^{\S}$, Claudia Avello Simões-Pires ${ }^{\S}$, Mei Ji ${ }^{\dagger}$, Hongxiang Lou ${ }^{\dagger}$, Peihong Fan ${ }^{\dagger}, *$

Department of Natural Product Chemistry, Key Lab of Chemical Biology of Ministry of Education, School of Pharmaceutical Sciences, Shandong University, Jinan 250012, China

§School of Pharmaceutical Sciences, University of Geneva, University of Lausanne, Quai Ernest Ansermet, 30, CH-1211 Geneva 4, Switzerland 


\section{List of supporting information}

Figure S1. ${ }^{1} \mathrm{H}$ NMR spectrum $(600 \mathrm{MHz})$ of 2 in $\mathrm{CD}_{3} \mathrm{OD}$.

Figure S2. ${ }^{13} \mathrm{C}$ NMR spectrum $(150 \mathrm{MHz})$ of 2 in $\mathrm{CD}_{3} \mathrm{OD}$.

Figure S3. HSQC spectrum $(600 \mathrm{MHz})$ of 2 in $\mathrm{CD}_{3} \mathrm{OD}$.

Figure S4. HMBC spectrum $(600 \mathrm{MHz})$ of 2 in $\mathrm{CD}_{3} \mathrm{OD}$.

Figure S5. HRESIMS spectrum of 2.

Figure S6. IR ( $\mathrm{KBr}$ disc) spectrum of 2.

Figure S7. ${ }^{1} \mathrm{H}$ NMR spectrum $(600 \mathrm{MHz})$ of 5 in $\mathrm{CD}_{3} \mathrm{OD}$.

Figure S8. ${ }^{13} \mathrm{C}$ NMR spectrum $(150 \mathrm{MHz})$ of 5 in $\mathrm{CD}_{3} \mathrm{OD}$.

Figure S9. HSQC spectrum $(600 \mathrm{MHz})$ of 5 in $\mathrm{CD}_{3} \mathrm{OD}$.

Figure S10. HMBC spectrum $(600 \mathrm{MHz})$ of 5 in $\mathrm{CD}_{3} \mathrm{OD}$.

Figure S11. HRESIMS spectrum of 5.

Figure S12. IR ( $\mathrm{KBr}$ disc) spectrum of 5.

Figure S13. ${ }^{1} \mathrm{H}$ NMR spectrum $(600 \mathrm{MHz})$ of 8 in $\mathrm{CD}_{3} \mathrm{OD}$.

Figure S14. ${ }^{13} \mathrm{C}$ NMR spectrum $(150 \mathrm{MHz})$ of 8 in $\mathrm{CD}_{3} \mathrm{OD}$.

Figure S15. HSQC spectrum $(600 \mathrm{MHz})$ of 8 in $\mathrm{CD}_{3} \mathrm{OD}$.

Figure S16. HMBC spectrum $(600 \mathrm{MHz})$ of 8 in $\mathrm{CD}_{3} \mathrm{OD}$.

Figure S17. HRESIMS spectrum of 8.

Figure S18. IR ( $\mathrm{KBr}$ disc) spectrum of $\mathbf{8}$.

Figure S19. ${ }^{1} \mathrm{H}$ NMR spectrum $(600 \mathrm{MHz})$ of $\mathbf{1 0}$ in $\mathrm{CD}_{3} \mathrm{OD}$.

Figure S20. ${ }^{13} \mathrm{C}$ NMR spectrum $(150 \mathrm{MHz})$ of $\mathbf{1 0}$ in $\mathrm{CD}_{3} \mathrm{OD}$.

Figure S21. HSQC spectrum $(600 \mathrm{MHz})$ of $\mathbf{1 0}$ in $\mathrm{CD}_{3} \mathrm{OD}$.

Figure S22. HMBC spectrum $(600 \mathrm{MHz})$ of 10in $\mathrm{CD}_{3} \mathrm{OD}$.

Figure S23. HRESIMS spectrum of $\mathbf{1 0}$.

Figure S24. IR ( $\mathrm{KBr}$ disc) spectrum of $\mathbf{1 0}$. 


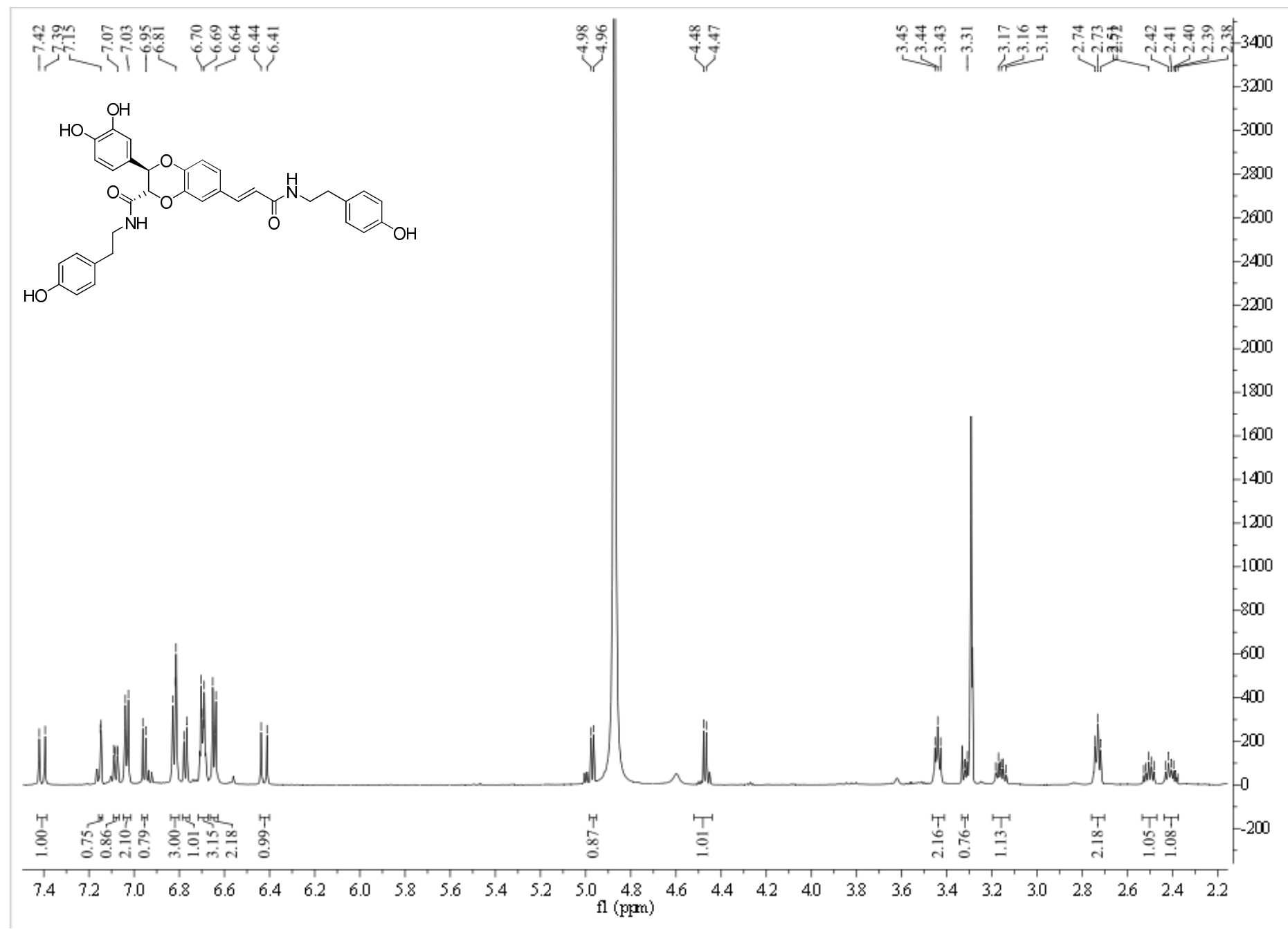

Figure S1. ${ }^{1} \mathrm{H}$ NMR spectrum $(600 \mathrm{MHz})$ of 2 in $\mathrm{CD}_{3} \mathrm{OD}$. 


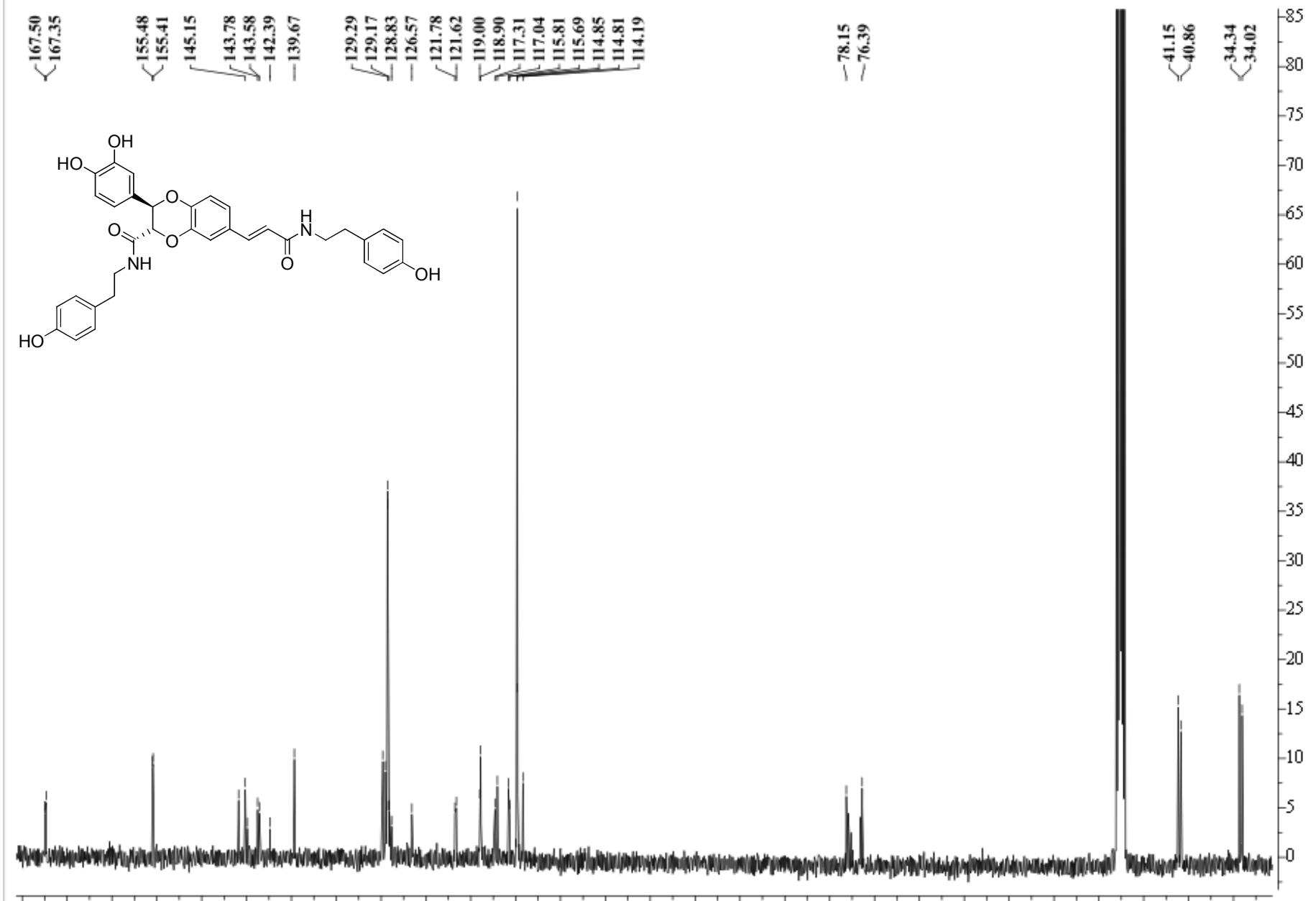

\begin{tabular}{llllllllllllllllllllllllllllllllllllll}
\hline 100 & 165 & 160 & 155 & 150 & 145 & 140 & 135 & 130 & 125 & 120 & 115 & 110 & 105 & 100 & 95 & 90 & 85 & 80 & 75 & 70 & 65 & 60 & 55 & 50 & 45 & 40 & 35
\end{tabular}

Figure S2. ${ }^{13} \mathrm{C}$ NMR spectrum $(150 \mathrm{MHz})$ of 2 in $\mathrm{CD}_{3} \mathrm{OD}$. 


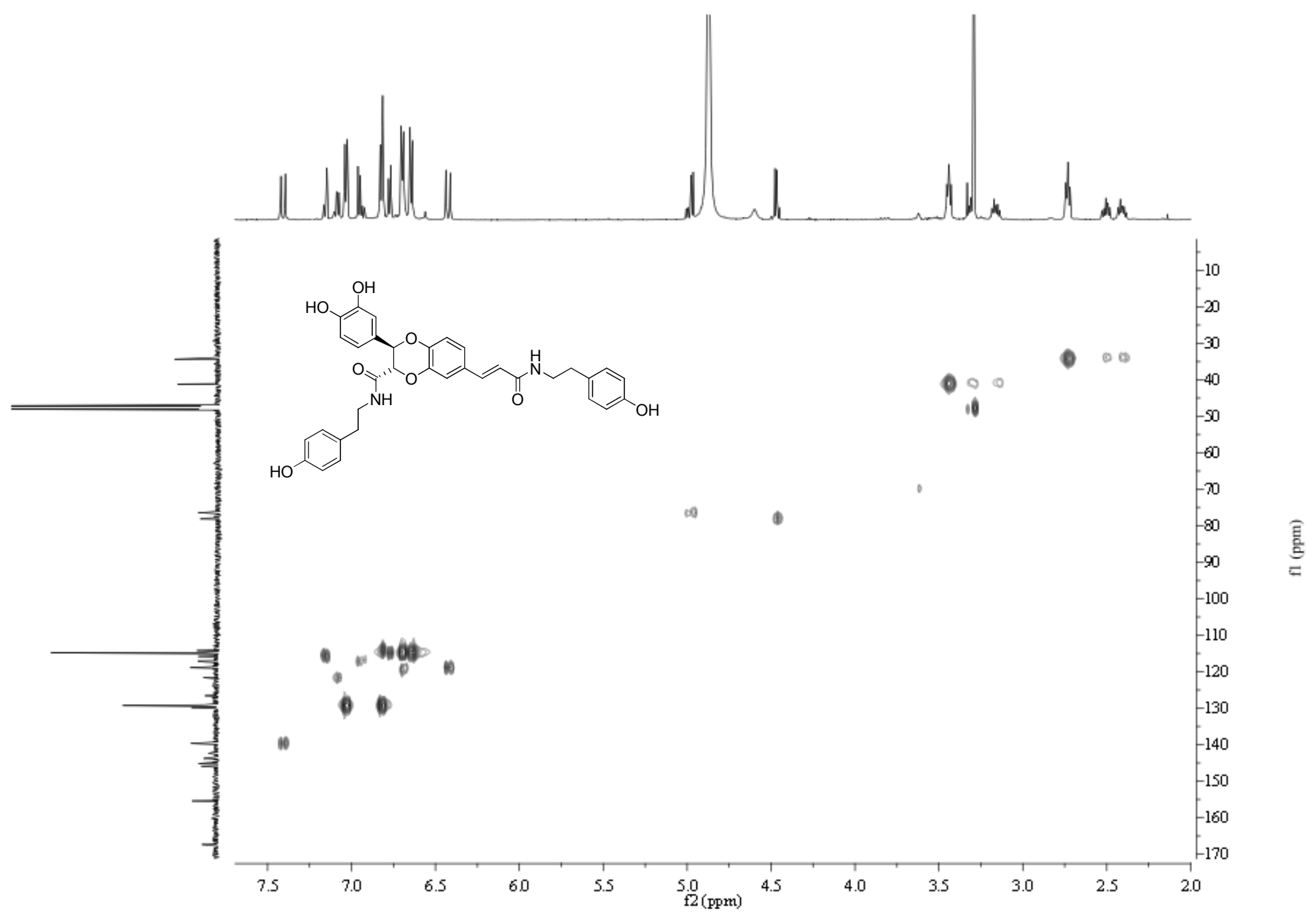

Figure S3. HSQC spectrum $(600 \mathrm{MHz})$ of 2 in $\mathrm{CD}_{3} \mathrm{OD}$. 


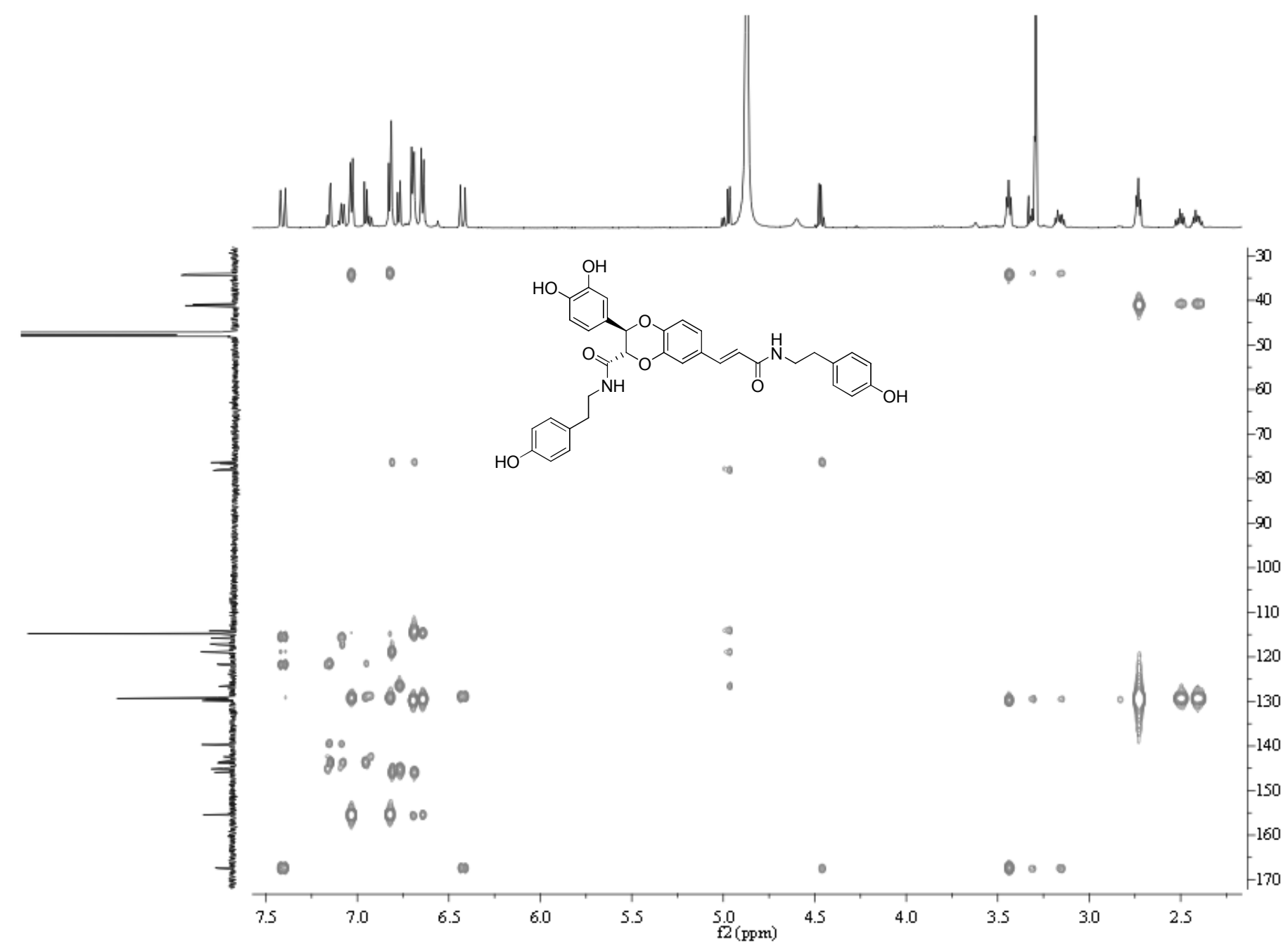

衰

Figure S4. $\mathrm{HMBC}$ spectrum $(600 \mathrm{MHz})$ of 2 in $\mathrm{CD}_{3} \mathrm{OD}$. 


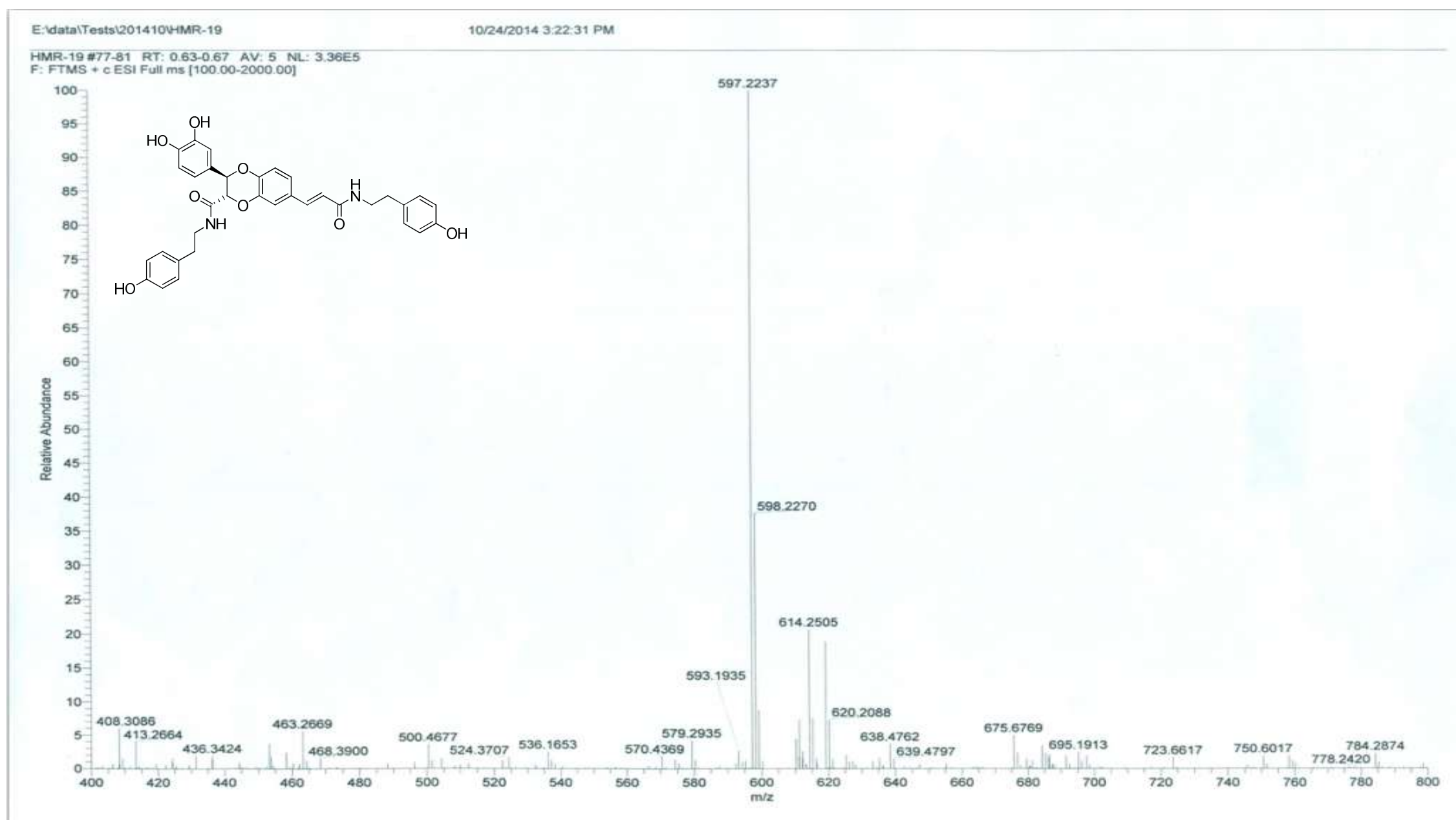

Figure S5. HRESIMS spectrum of 2. 
Center of Drug Analysis and Test, School of Pharmacy, SDU

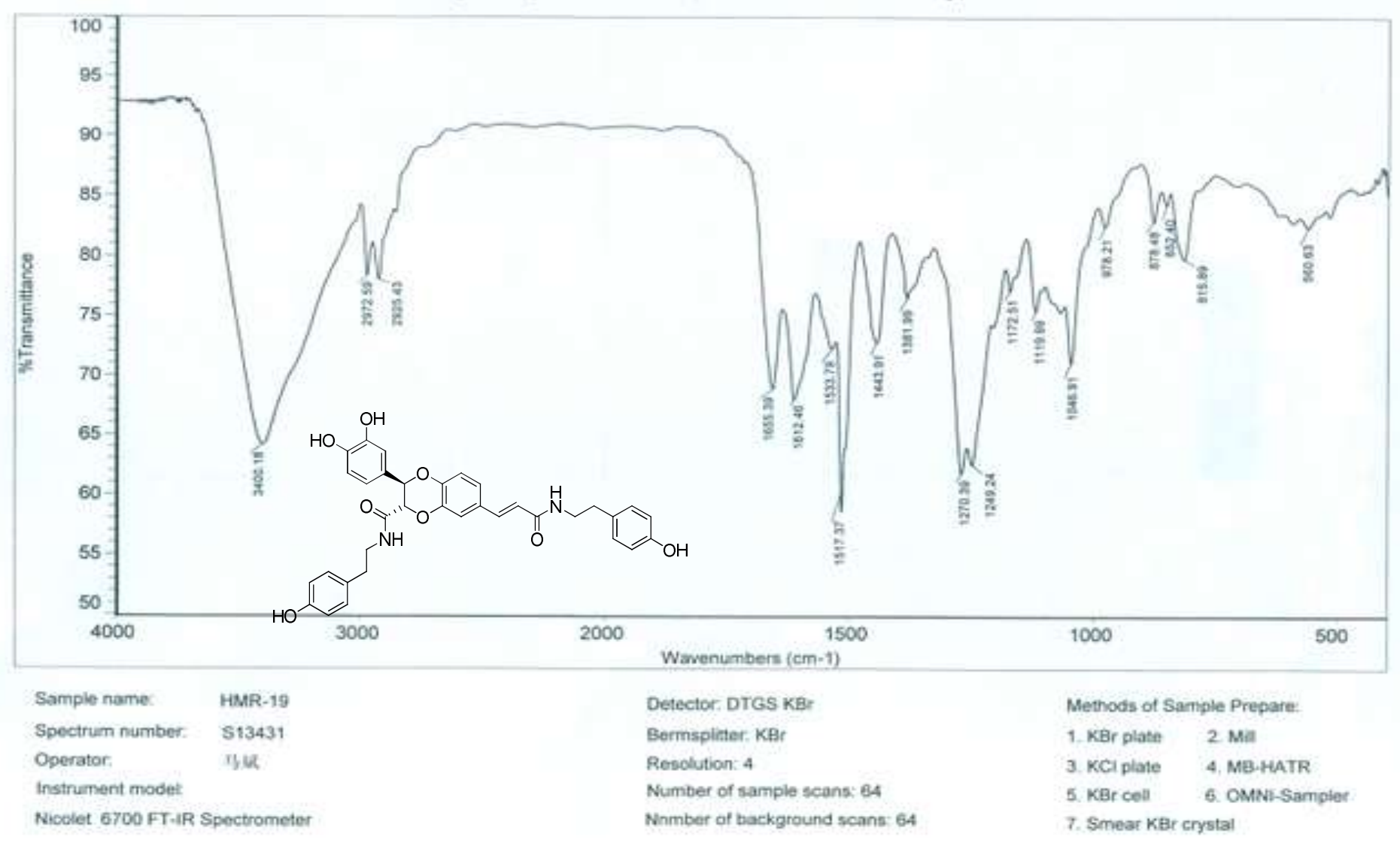

Figure S6. IR (KBr disc) spectrum of 2. 


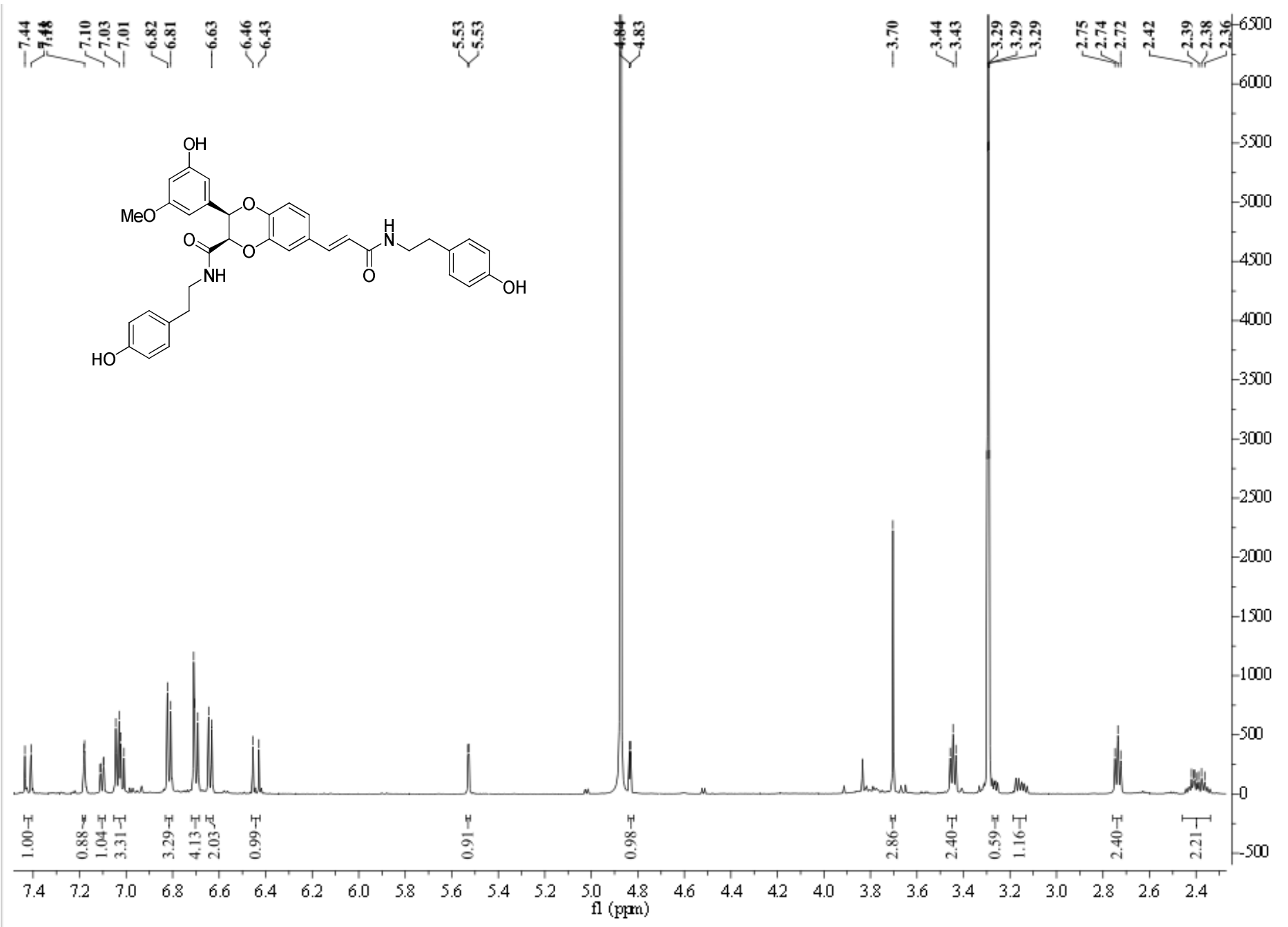

Figure S7. ${ }^{1} \mathrm{H}$ NMR spectrum $(600 \mathrm{MHz})$ of 5 in $\mathrm{CD}_{3} \mathrm{OD}$. 


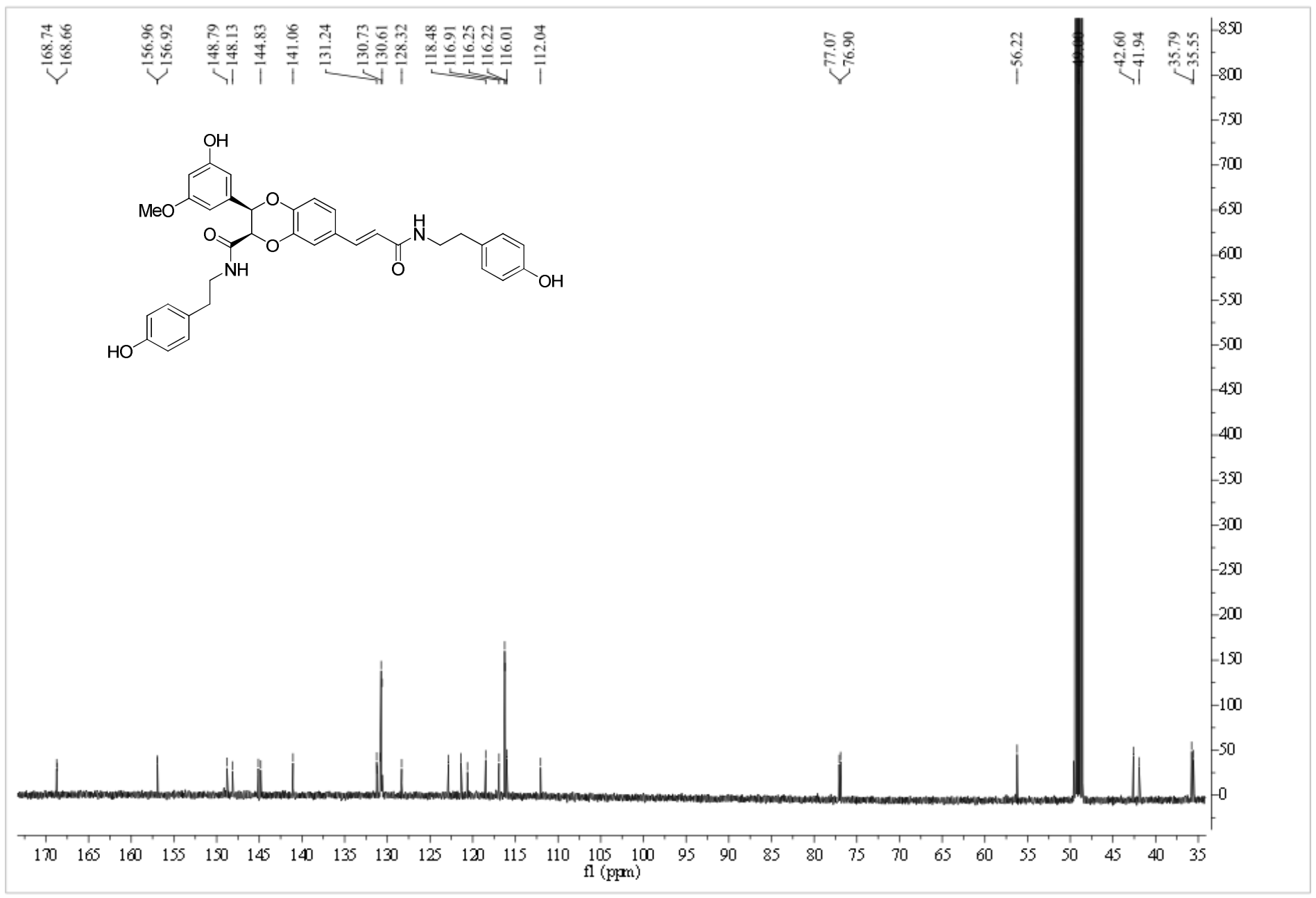

Figure S8. ${ }^{13} \mathrm{C}$ NMR spectrum $(150 \mathrm{MHz})$ of 5 in $\mathrm{CD}_{3} \mathrm{OD}$. 


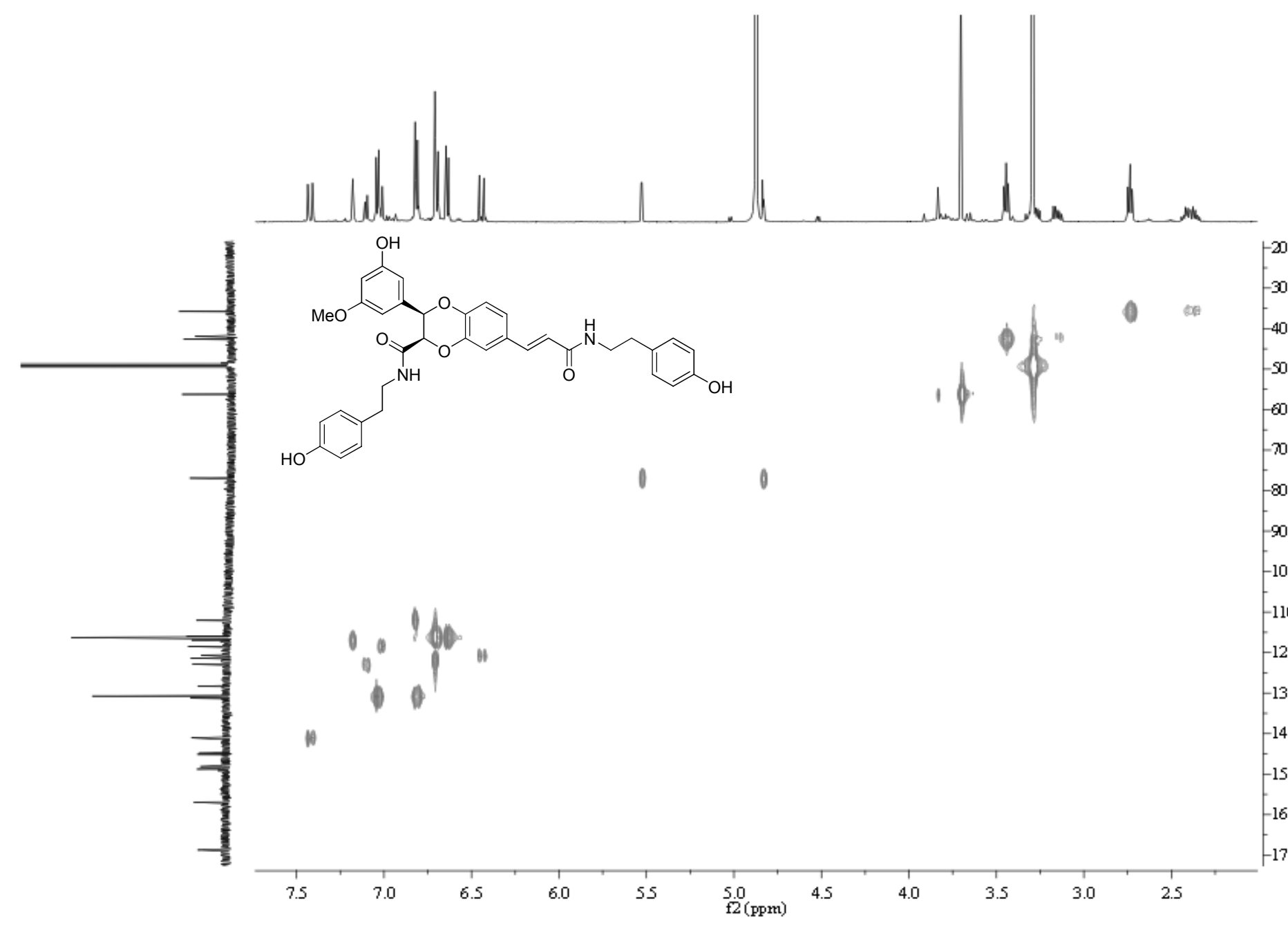

言

Figure S9. HSQC spectrum (600 MHz) of 5 in $\mathrm{CD}_{3} \mathrm{OD}$. 


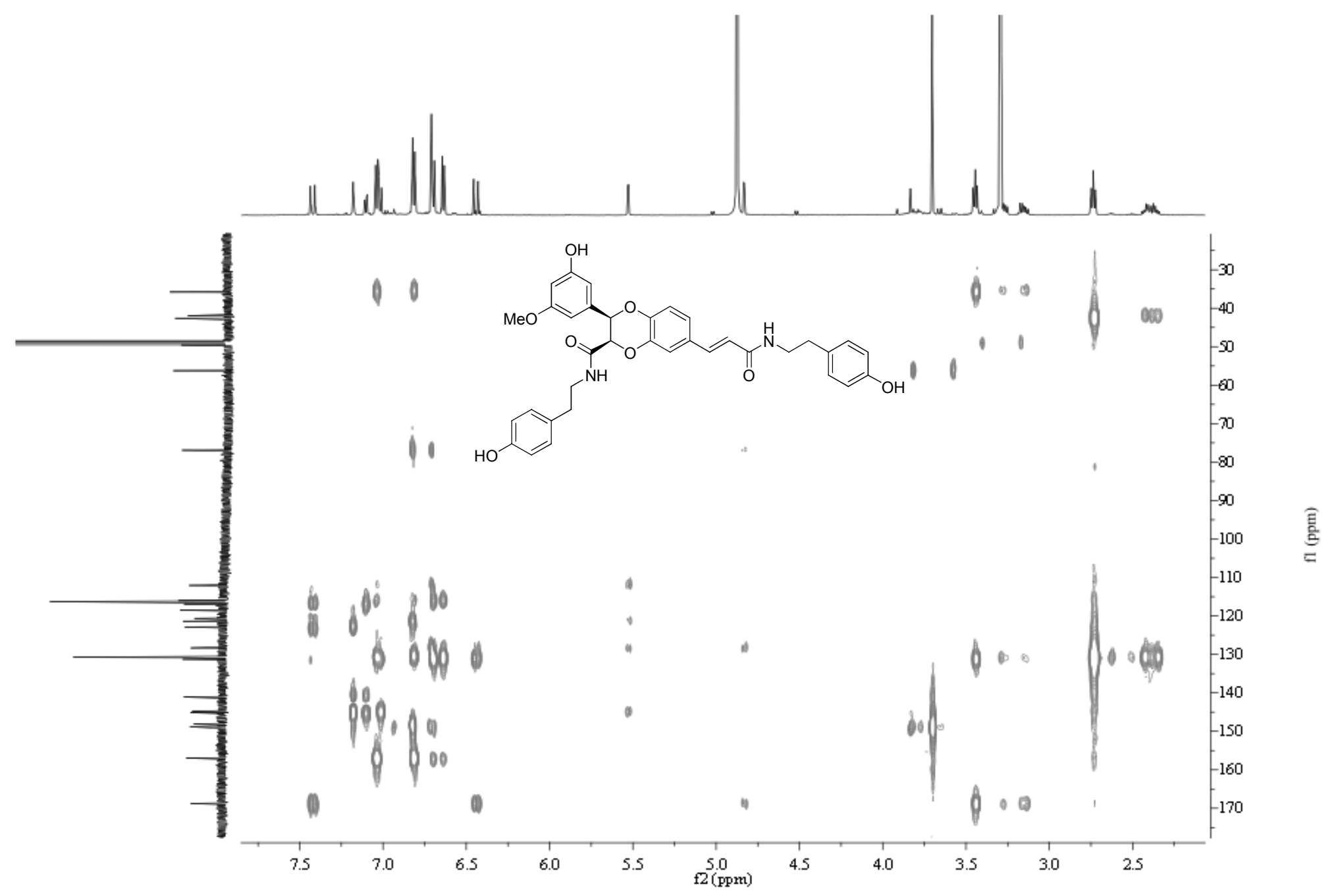

Figure S10. HMBC spectrum $(600 \mathrm{MHz})$ of 5 in $\mathrm{CD}_{3} \mathrm{OD}$. 


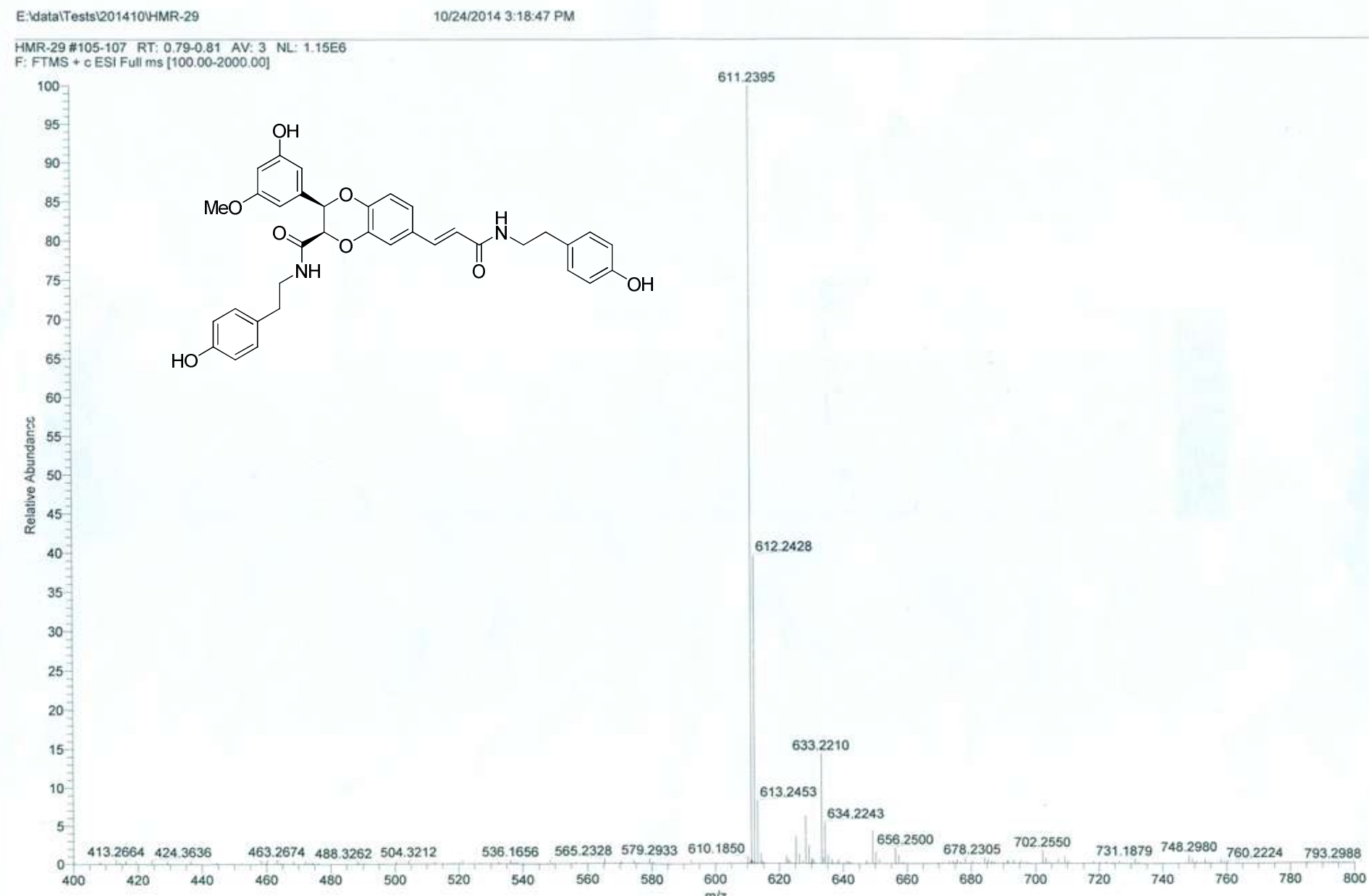

Figure S11. HRESIMS spectrum of 5. 
Center of Drug Analysis and Test, School of Pharmacy, SDU

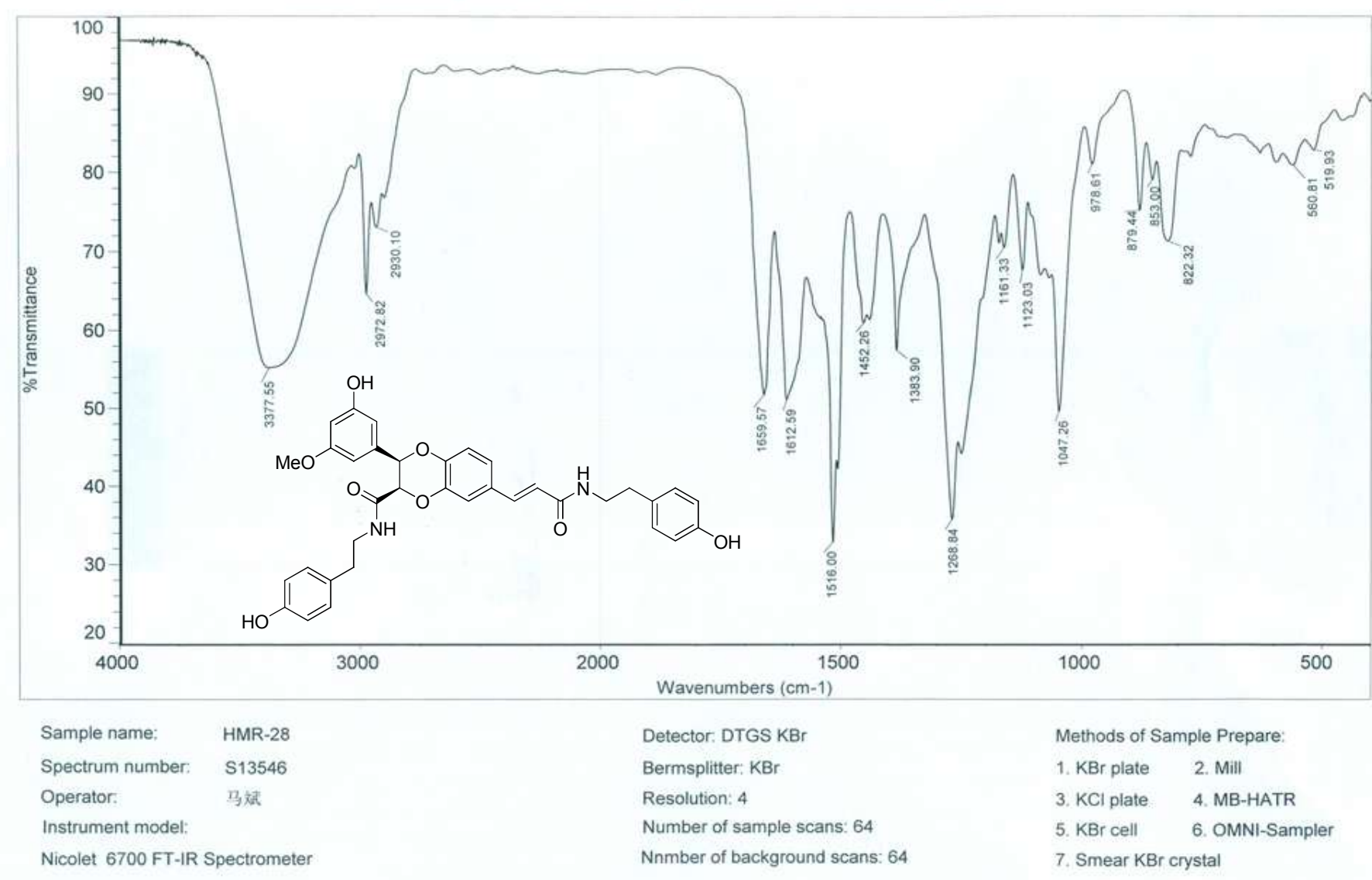

Figure S12. IR (KBr disc) spectrum of 5. 


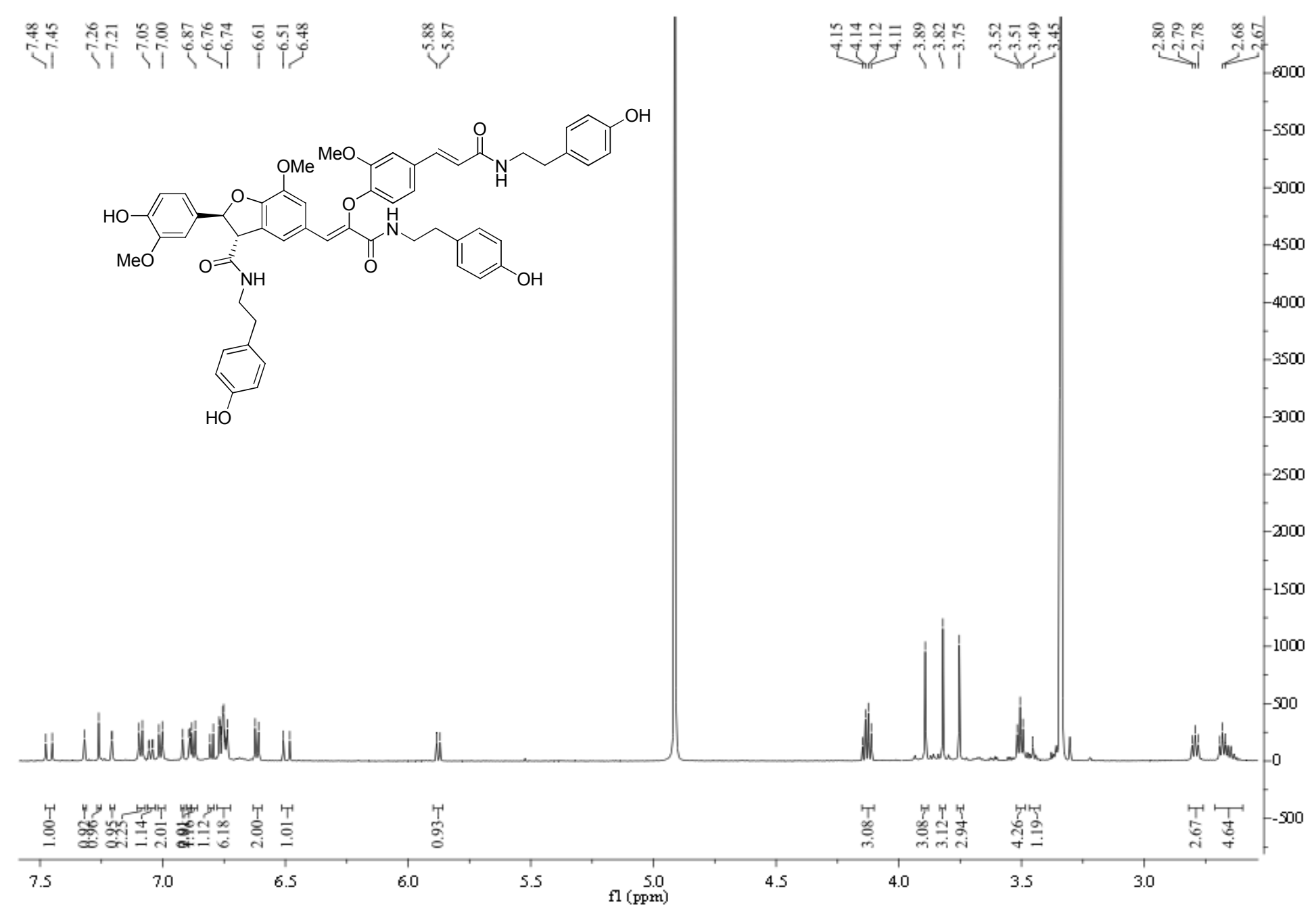

Figure S13. ${ }^{1} \mathrm{H}$ NMR spectrum $(600 \mathrm{MHz})$ of 8 in $\mathrm{CD}_{3} \mathrm{OD}$. 

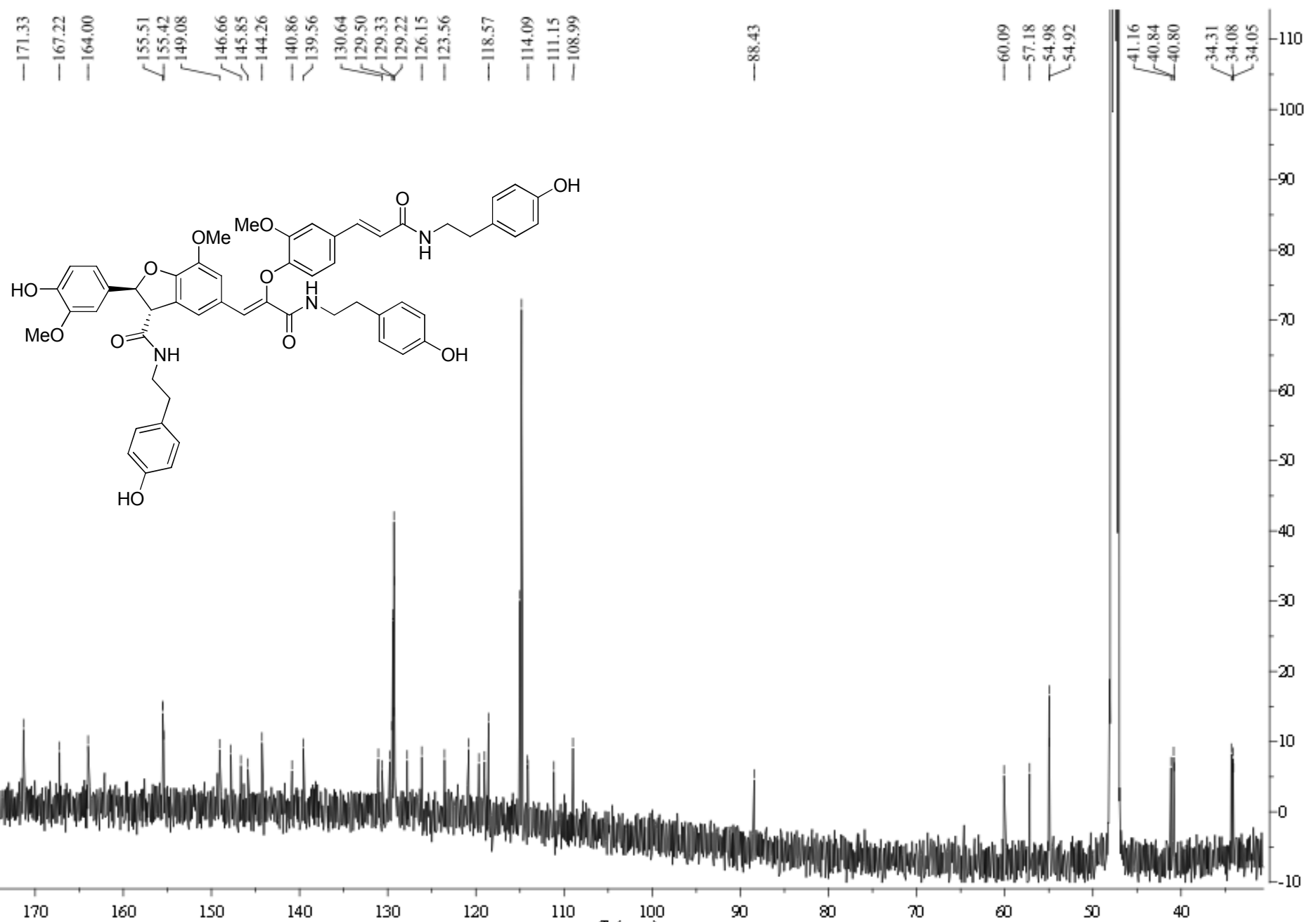

$170 \quad 160$ 150 $110 \quad 100$

Figure S14. ${ }^{13} \mathrm{C}$ NMR spectrum $(150 \mathrm{MHz})$ of 8 in $\mathrm{CD}_{3} \mathrm{OD}$. 


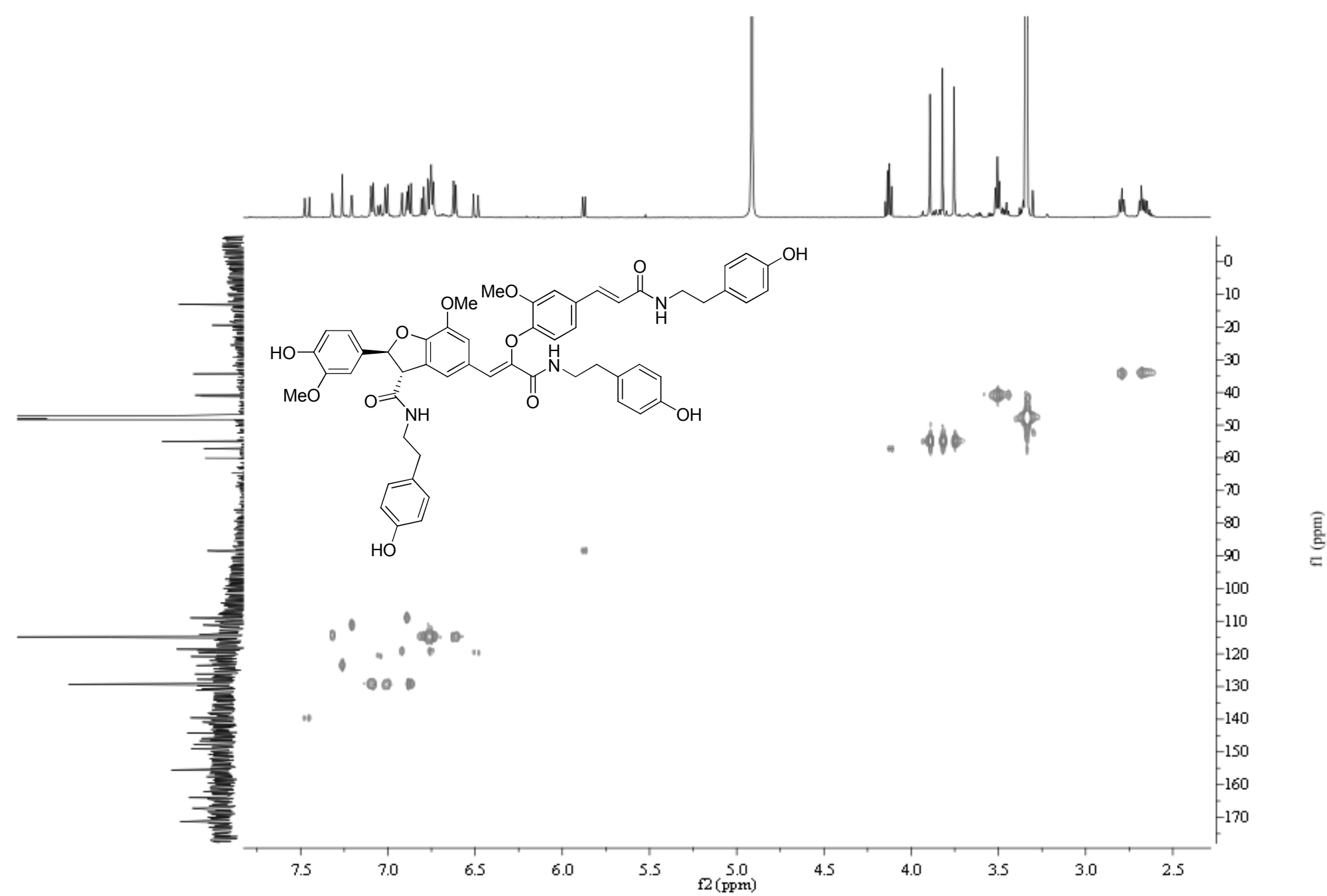

Figure S15. HSQC spectrum (600 MHz) of 8 in $\mathrm{CD}_{3} \mathrm{OD}$. 


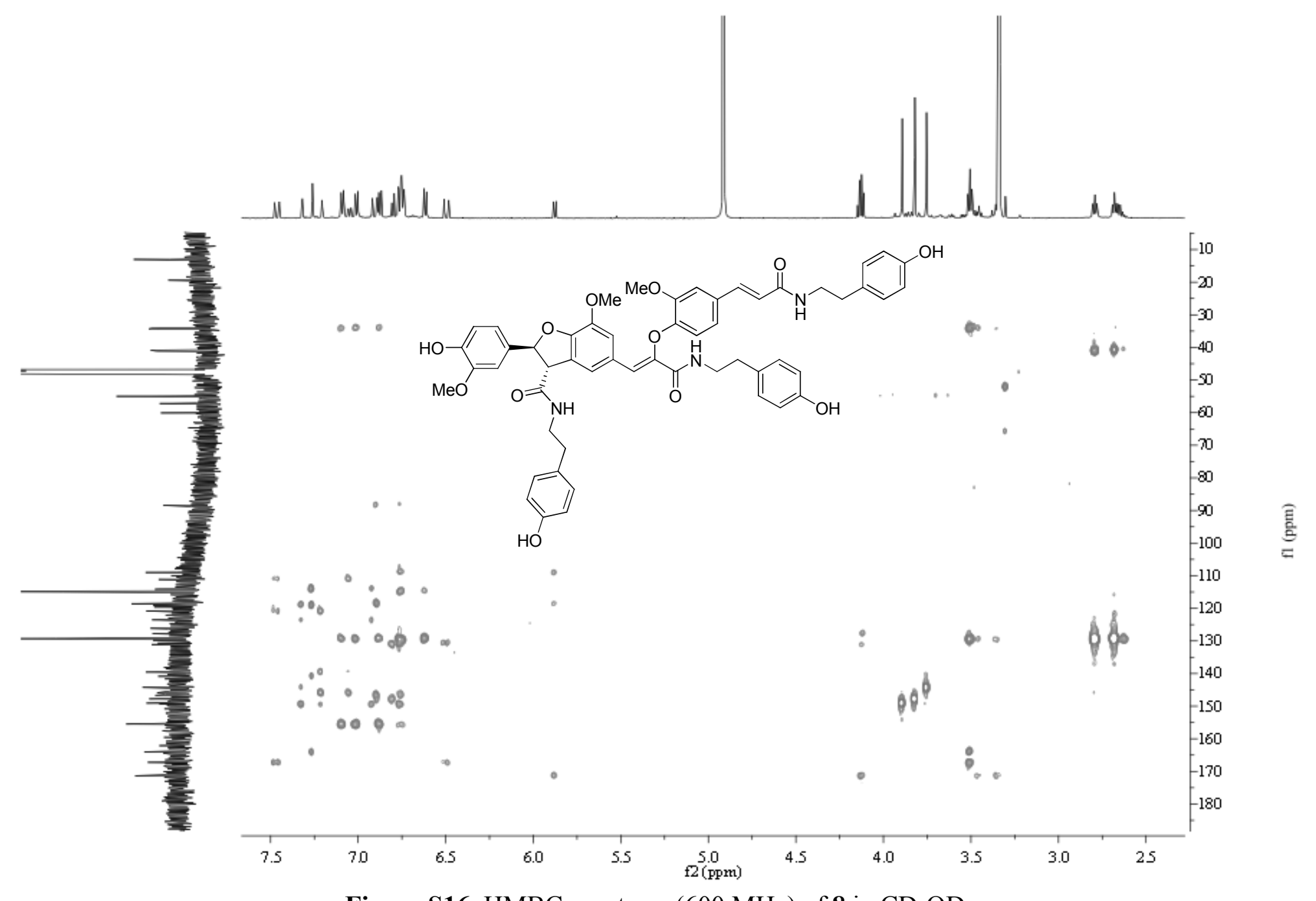

Figure S16. $\mathrm{HMBC}$ spectrum $(600 \mathrm{MHz})$ of 8 in $\mathrm{CD}_{3} \mathrm{OD}$. 


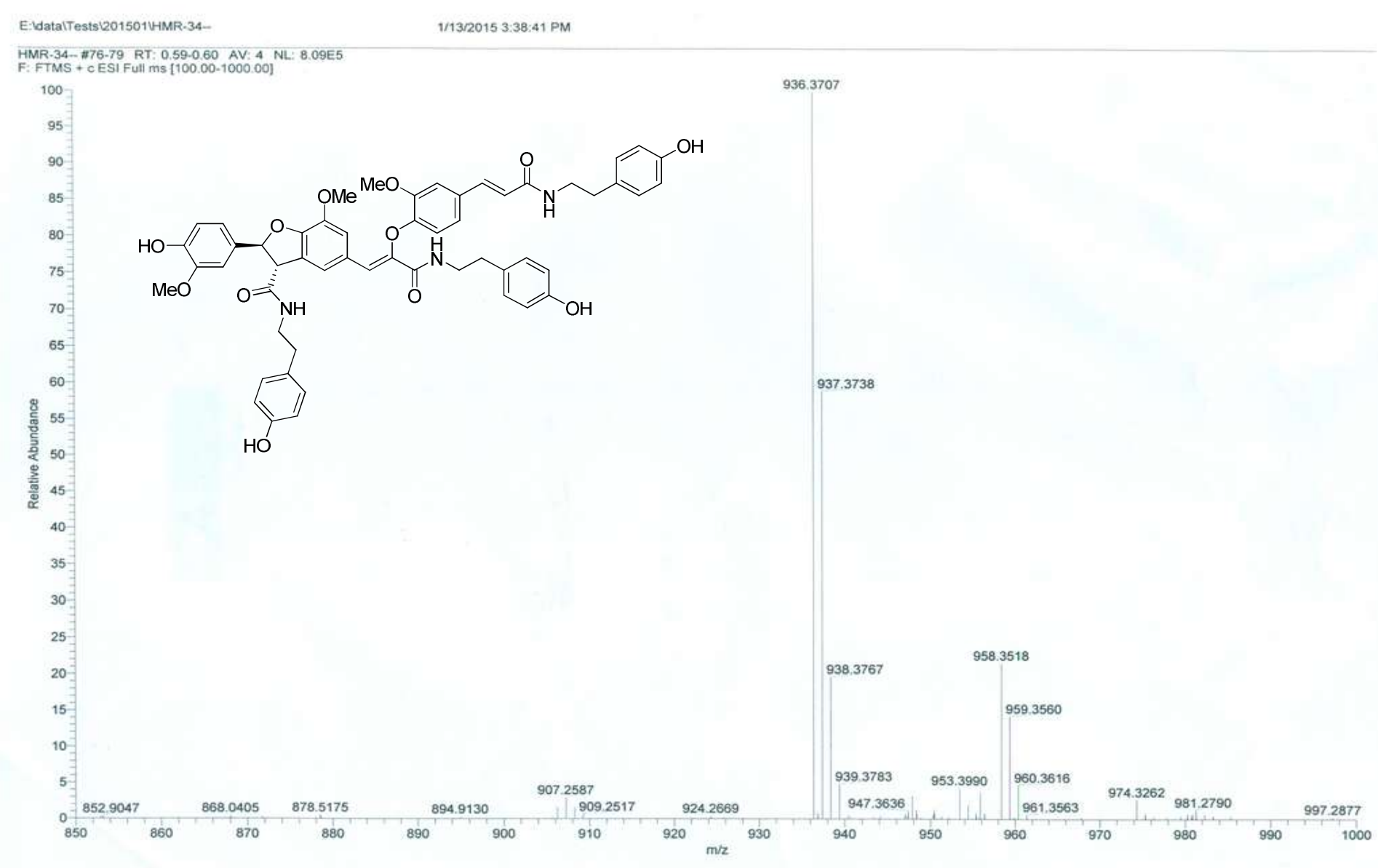

Figure S17. HRESIMS spectrum of 8 . 
Center of Drug Analysis and Test, School of Pharmacy, SDU

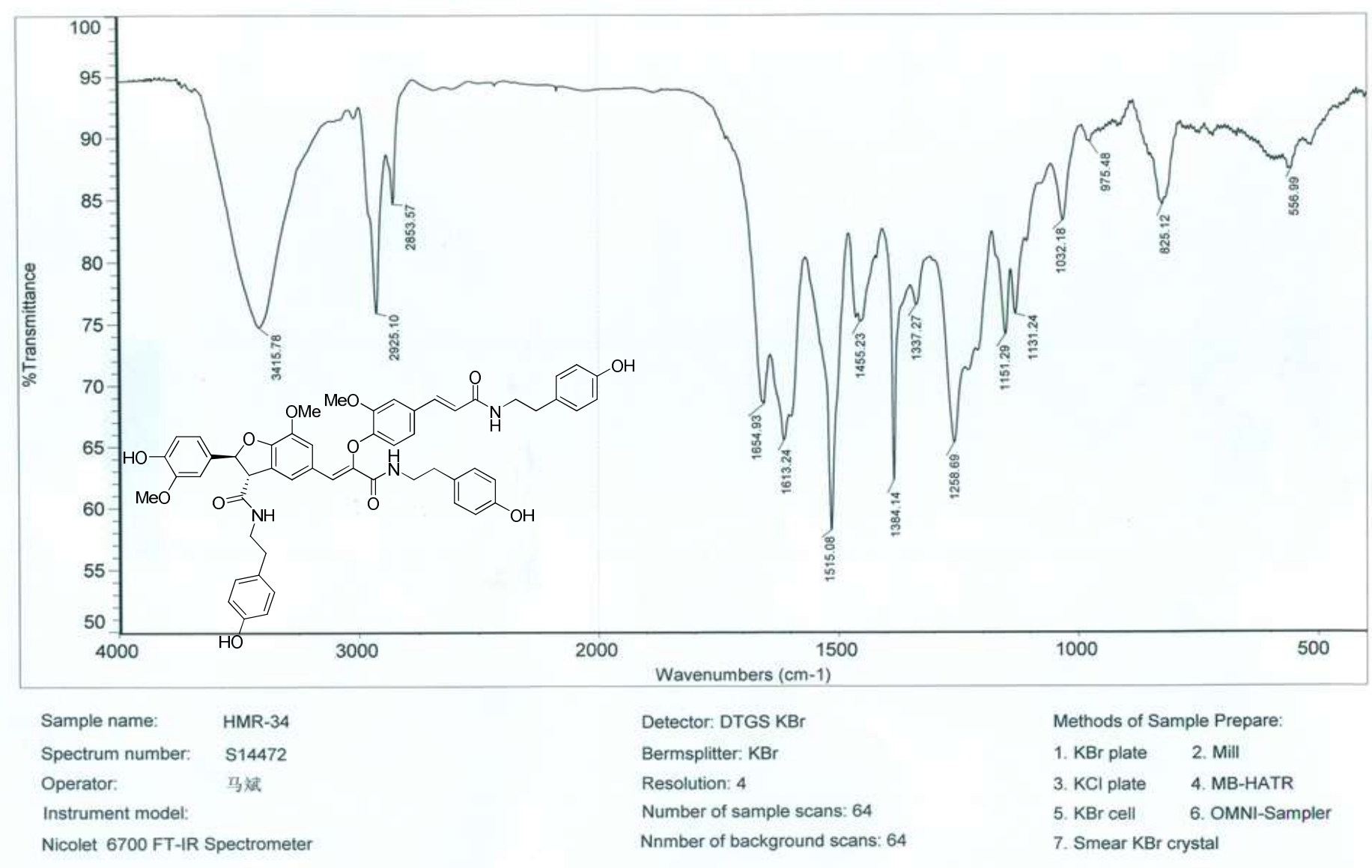

Figure S18. IR ( $\mathrm{KBr}$ disc) spectrum of $\mathbf{8}$. 


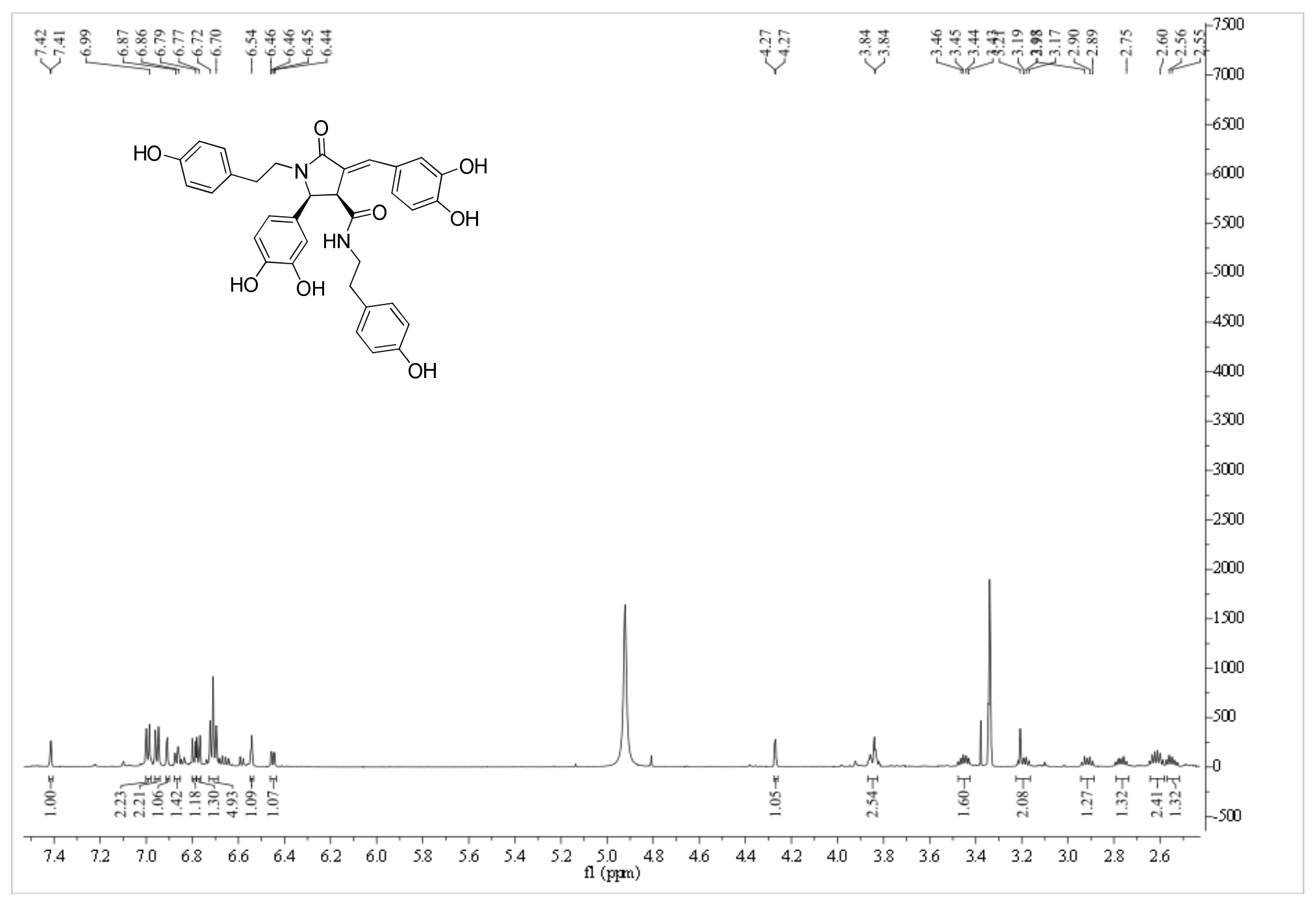

Figure S19. ${ }^{1} \mathrm{H}$ NMR spectrum $(600 \mathrm{MHz})$ of $\mathbf{1 0}$ in $\mathrm{CD}_{3} \mathrm{OD}$. 


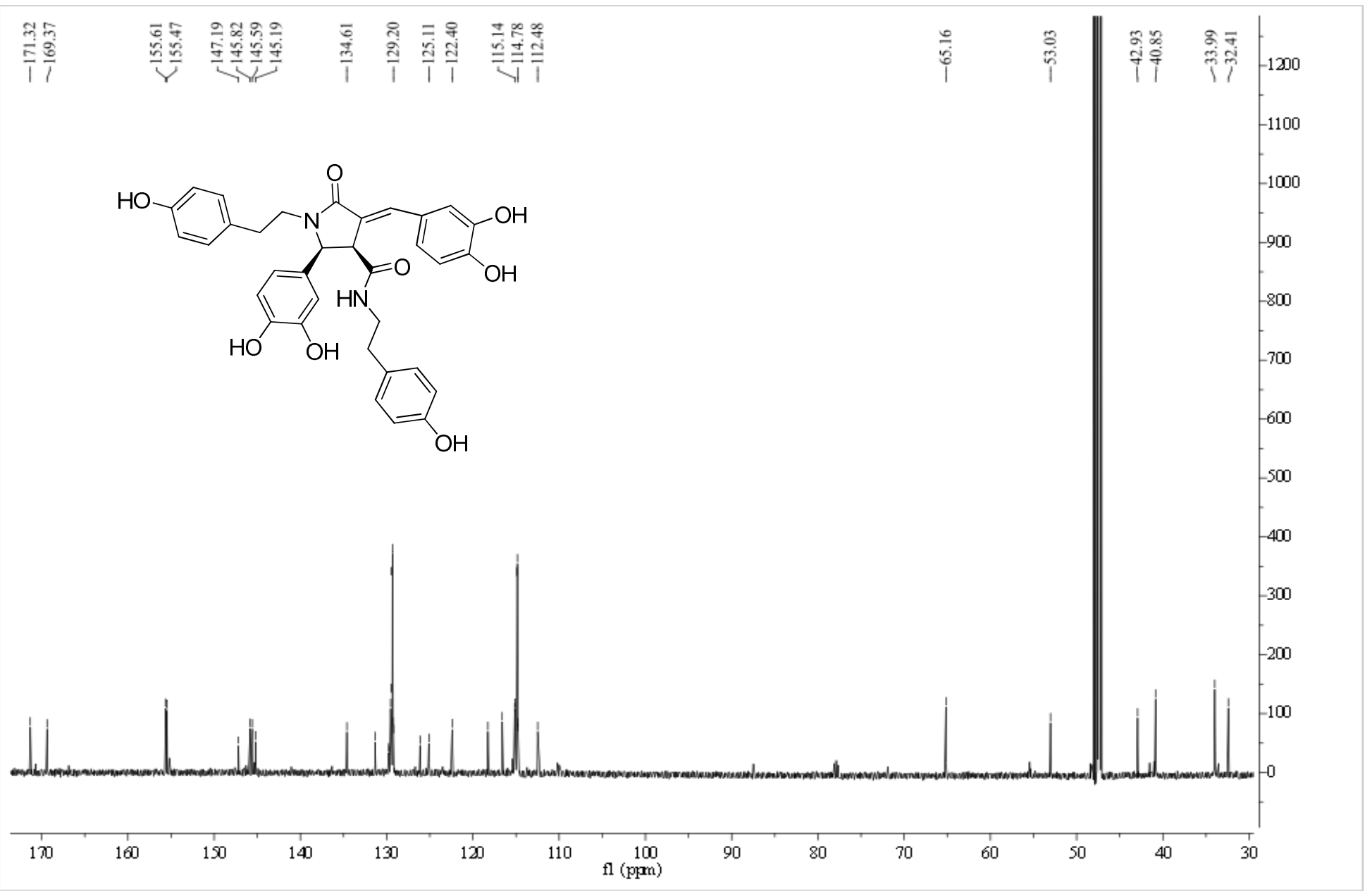

Figure S20. ${ }^{13} \mathrm{C}$ NMR spectrum $(150 \mathrm{MHz})$ of $\mathbf{1 0}$ in $\mathrm{CD}_{3} \mathrm{OD}$. 


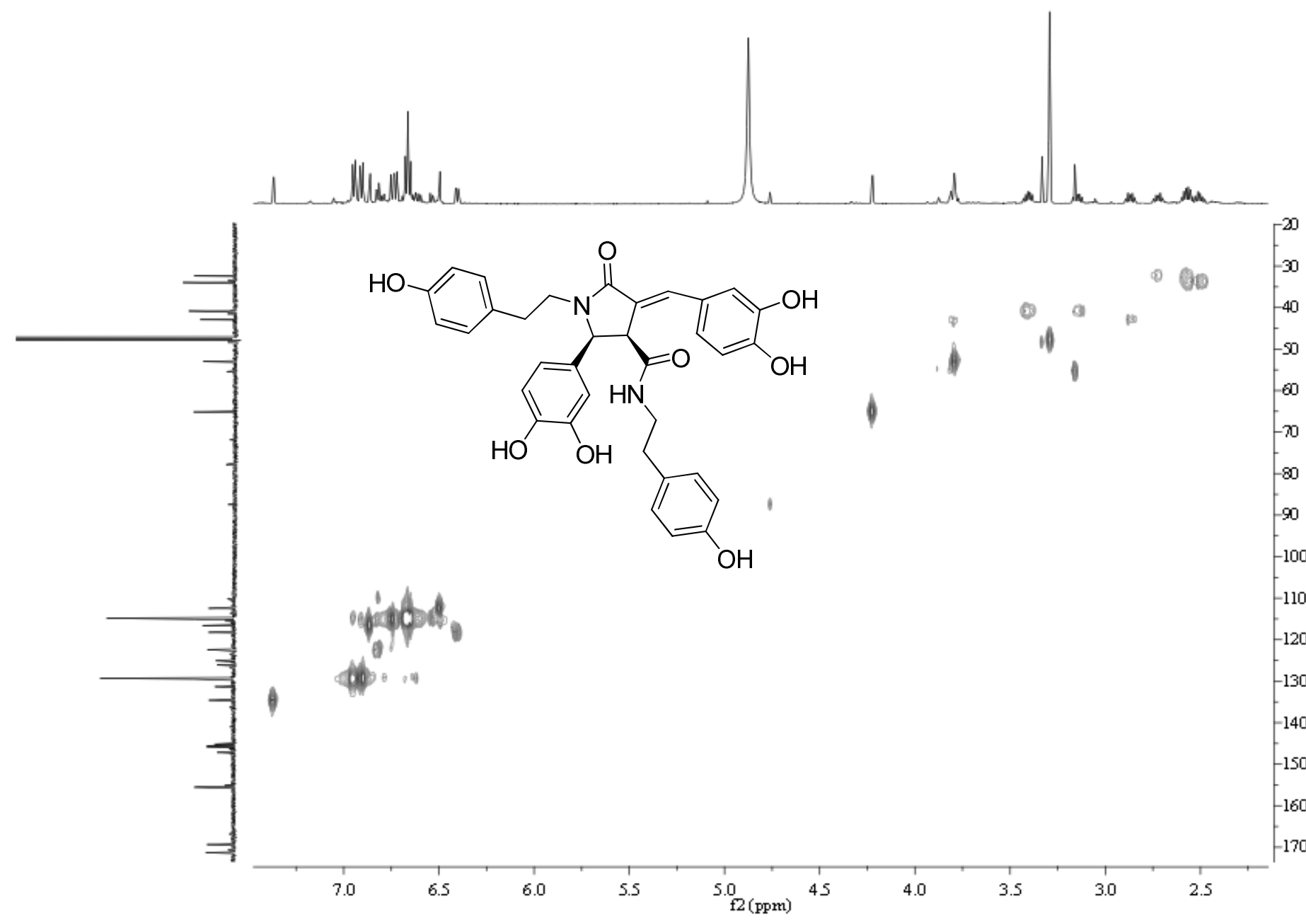

Figure S21. HSQC spectrum $(600 \mathrm{MHz})$ of $\mathbf{1 0}$ in $\mathrm{CD}_{3} \mathrm{OD}$. 


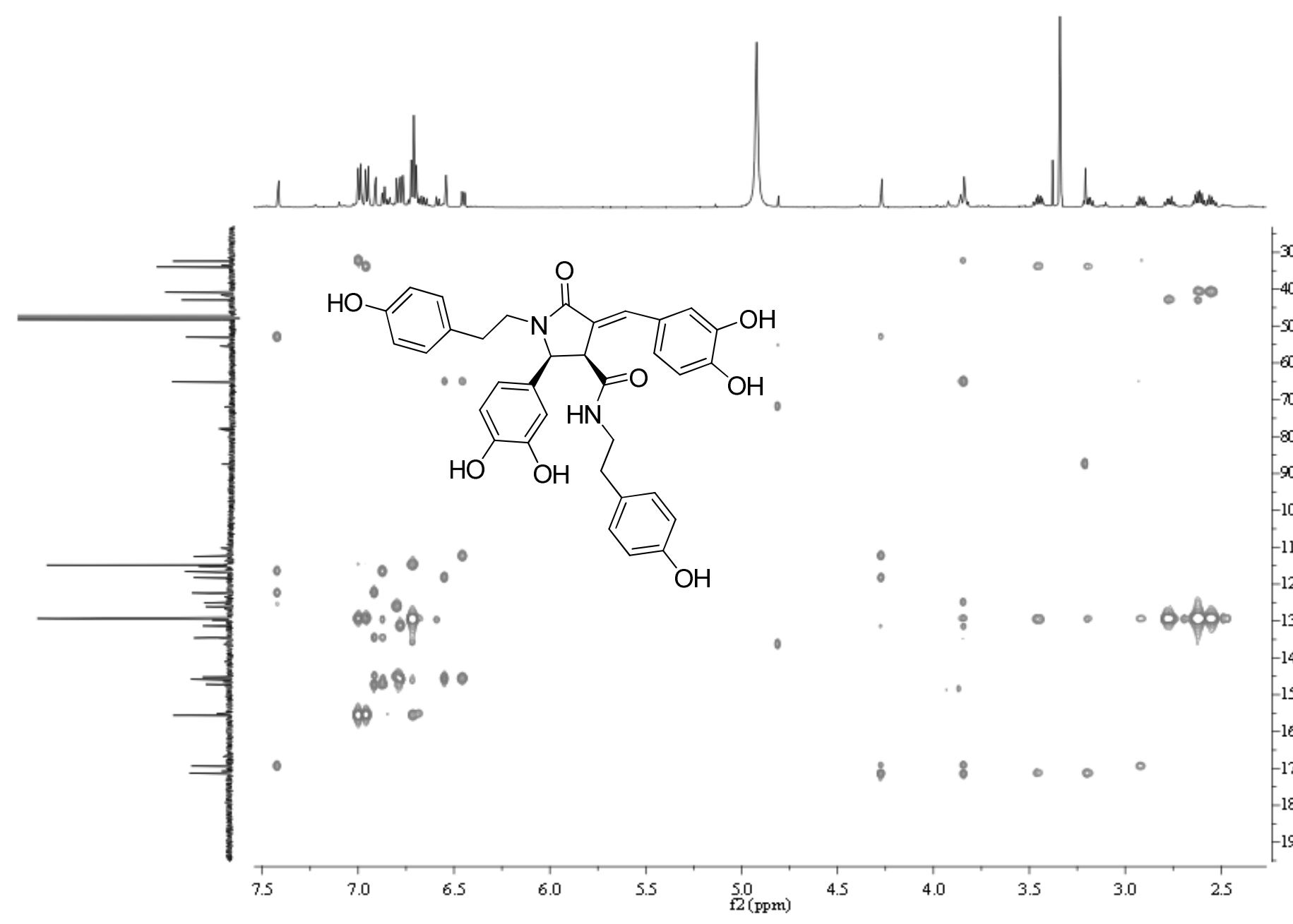

Figure S22. HMBC spectrum $(600 \mathrm{MHz})$ of $\mathbf{1 0}$ in $\mathrm{CD}_{3} \mathrm{OD}$. 


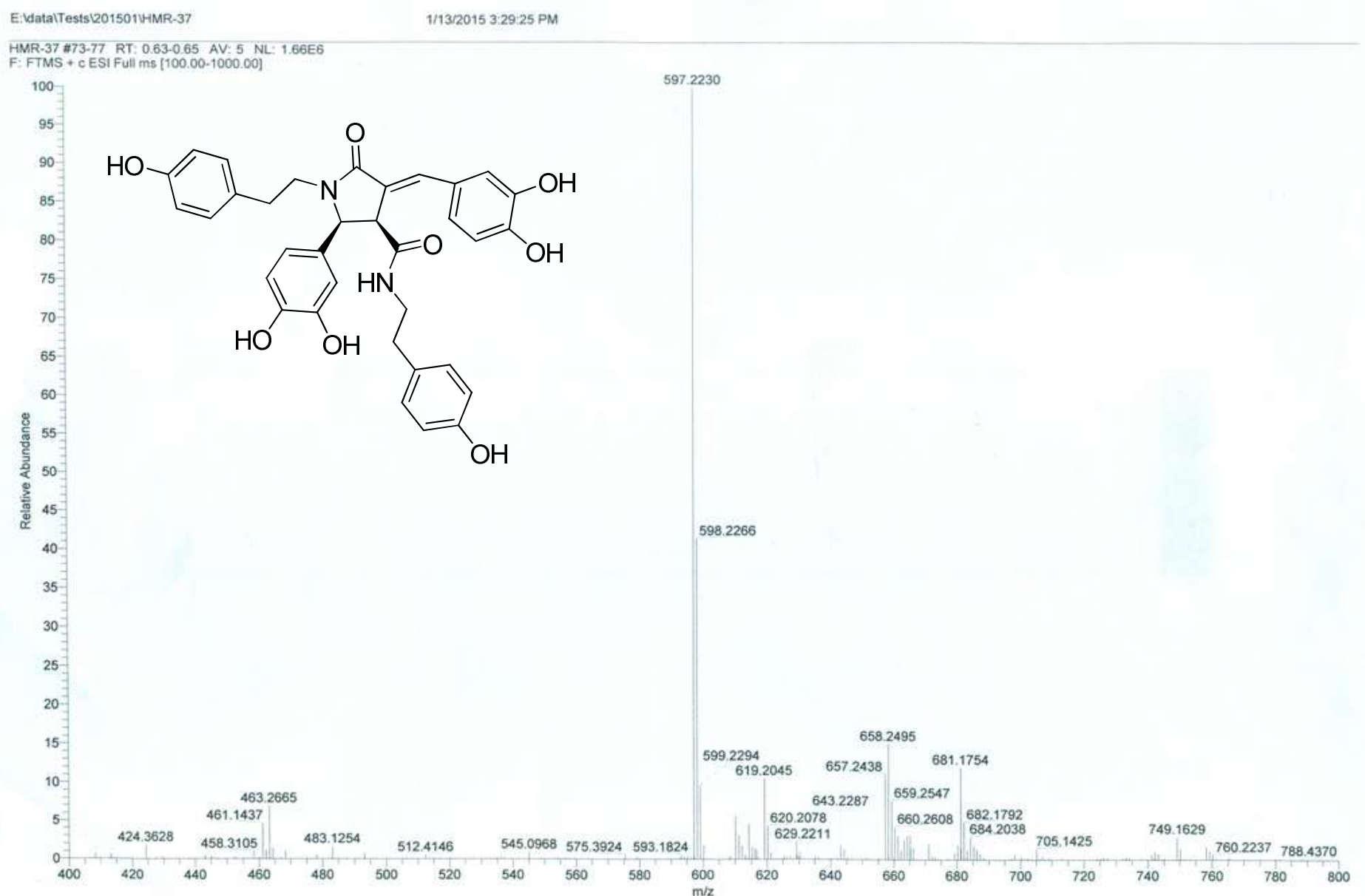

Figure S23. HRESIMS spectrum of $\mathbf{1 0}$ 
Center of Drug Analysis and Test, School of Pharmacy, SDU

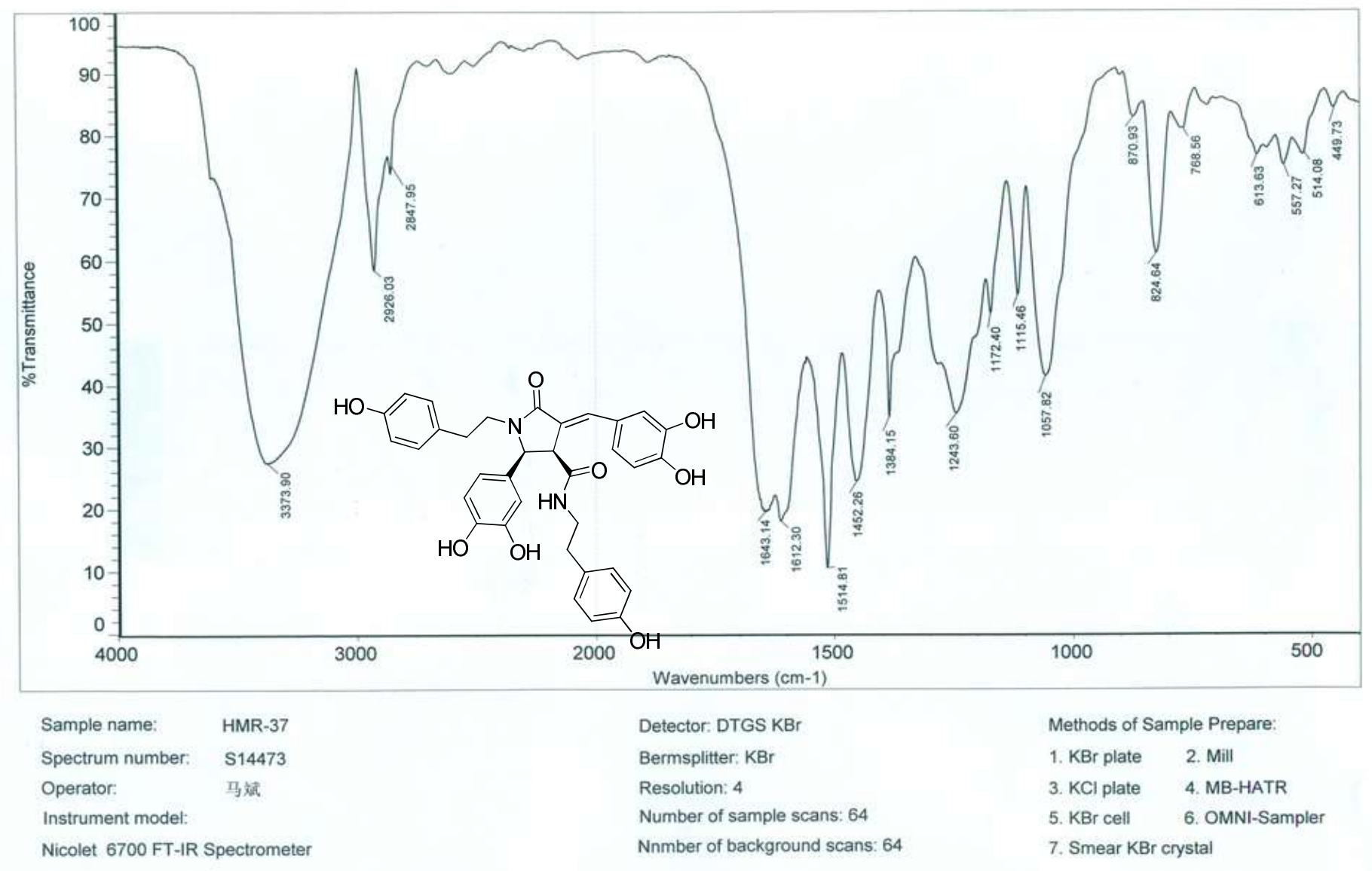

Figure S24. IR (KBr disc) spectrum of $\mathbf{1 0}$. 